\title{
Impact of an educational training program on nurses knowledge and performance about cardiovascular disease in Department of Cardiology at Assiut University Hospital.
}

\author{
Safaa Omran Kamal, Soad Sayed Bayomy, \& Asmaa Kamal Hassan \\ B.S. Professional Nurse In Coronary Care Unit Assiut University Hospital. \\ Assistant Professor of Community Health Nursing Faculty of Nursing, Assiut University. \\ Lecturer of Community Health Nursing Faculty of Nursing, Assiut University
}

\begin{abstract}
:
Cardiovascular diseases (CVD) have become the leading cause of death worldwide. "Continuing education in nursing contributes as profession's currency". Aim of the study: The study conducted to assess the knowledge and performance of nurses about cardiovascular diseases, develop, implement and evaluate an educational in- service training program for nurses working with cardiovascular patients. Subjects and methods: Quasi-experimental research design was used. The study included 60 nurses working in Cardiovascular Department at Assiut University Hospital. The study tools for data collection were self- administrated knowledge questionnaire sheet and observational checklist. The study was carried out on 3 phases: preparatory, implementation and evaluation phase. Results:The main results revealed that nurses' total mean scores of knowledge and performance throughout intervention program phases have demonstrated an improvement from a pre-program. with highly statistically significant ( $\mathrm{p}=0.005$ ). Conclusion: It was concluded, that cardiovascular nurses who are working in Cardiovascular Department at Assiut University Hospital were improved their knowledge and performance related to caring of patient with cardiovascular diseases. Recommendations: Cardiovascular nurses should update their knowledge and performance through continued nursing education and training program. Newly employed nurses in Cardiovascular Department must complete a test of basic knowledge and skills before assuming independent responsibility for patient care.
\end{abstract}

Keywords: Cardiovascular disease, Cardiopulmonary Resuscitation, Electrocardiogram.

\section{Introduction:}

Cardiovascular diseases (CVD) are considered the leading cause of death worldwide, and is an escalating problem in most Middle Eastern and other Western countries. Heart diseases are the leading cause of death for both men and women. The total numbers of deaths due to cardiovascular disease were 17.3 million a year according to the World Health Organization (WHO, 2008). Every year, 715,000 Americans have heart attacks. While 600,000 people die from heart diseases in the United States each year, (Mozaffarian et al, 2013).

Cardiovascular diseases alone kill almost 20 million people each year. In fact, cardiovascular diseases are the leading cause of death in the developing world. In Egypt, for example, heart disease-related mortality reached 210,000 in 2009 (WHO, 2011).

Cardiovascular diseases (CVD) means all the diseases of the heart and circulation including coronary heart diseases (angina and heart attack), and stroke (Michael, 2013).The majority of cardiovascular diseases (CVD) are caused by risk factors that can be controlled or treated, such as high blood pressure, cholesterol, overweight, obesity, tobacco use, lack of physical activity and diabetes. However, there are also some major CVD risk factors that cannot be controlled such as Age, Gender, Family history (Mendis et al., 2011).

The symptoms of cardiovascular diseases ranging from chest pain to sudden numbness of the face or arms. There are more than 60 forms of cardiovascular diseases, so possible signs may not be the same in all cases. In general, symptoms occur most frequently in the heart and brain, as well as in the legs, pelvis, or arms. Cardiovascular diseases may exist with no obvious symptoms or pain. When symptoms are present, they vary depending on the extent to which the normal flow of blood to the affected organ is interrupted.

Cardiovascular nurses play a key role in the evaluation of cardiovascular status, monitoring the hemodynamic functions and disease management. Nursing interventions have been shown to reduce patient stress and cardiovascular complications . Recent research findings suggest that morbidity and mortality in cardiac patients can be improved with a comprehensive treatment plan which has a nurse managed stress reduction plan (Ulmer, 2002).

Cardiovascular nurses receive specialized training to care for patients with a variety of cardiovascular ailments. They provide a range of services in several settings. Clinics, specialized inpatient units, diagnostic services and operating rooms all benefit 
from their expertise. Nurses also promote awareness and encourage healthy lifestyle choices (Chin, 2008). The American Nurses Association (ANA) states nursing is the protection, promotion, and optimization of health and abilities, prevention of illness and injury, alleviation of suffering through the diagnosis and treatment of human response, and advocacy in the care of individuals, families, communities, and populationshttp://en.wikipedia.org/wiki/Nursing cite_note-1 (Susan, 2009).

\section{Subjects and Methods:}

The present study was carried out to assess the knowledge, performance of nurses about cardiovascular diseases, develop, implement and evaluate an educational in-service training program for nurses working with cardiovascular patients in Cardiovascular Department at Assiut University Hospital.

Research design:

Quasi-experimental research design has been utilized in this study.

\section{Setting:}

The study was conducted in the Cardiovascular Departments, it consists of three places namely coronary care unit, inpatient unit and catheterization unit at Assiut University Hospital.

\section{Subjects:}

Total coverage sample include all nurses who are working in Cardiovascular Departments at Assiut University Hospital. The total of the study sample was 60 nurses work in the previously mentioned setting which include the following categories such as: 4 head nurse, 56 staff nurse and they were interviewed in the morning shift.

\section{Study tools:}

Data pertinent to the study were collected utilizing two different tools, namely a self-administered knowledge questionnaire sheet, and observation checklist for performance.

\section{1-Self-administered knowledge questionnaire sheet:}

A questionnaire sheet was designed by the researcher who visited the selected setting and was request the nurses to participate in the study through face-to-face interviews it was structured into three parts:

\section{The first part:}

Demographic data as name, age, place of work, level of education, years of experience and attendance of training course.

The second part:

It consisted of (17) questions regarding nurses' knowledge about cardiovascular diseases as definition, types and risk factors, knowledge related to cardiopulmonary resuscitation (CPR), Electrocardiogram (ECG), oxygen therapy and some drugs side effect.

\section{The third part:}

It consisted of (11) questions regarding nurses' knowledge about cardiovascular disease include questions regarding nurses' knowledge about health education provided by the nurse to the cardiac patient. These questions about; using nitroglycerine, using digoxn, using anti-clotting drug, the benefits of quitting smoking, the importance of a nutritional education, allowed foods for cardiovascular patients, how to control diabetes mellitus, control of high blood pressure, physical activity, sexual relationship and elimination.

Scoring system: For knowledge items, a complete correct answer was scored 1, incomplete and incorrect answer was scored zero. For each area of knowledge, the scores of the items were summed-up and the total divided by the number of the items, giving a mean score for the part. The score considered good if the percent score was $60 \%$ or more and satisfactory if the percent score was 50\%: $60 \%$ and poor if the percent score was $50 \%$ or less . This tool was used as pre, post and follow up tests.

\section{2-Observation checklist:}

An observation check-list was developed by the researcher in order to assess nurses performance related to specific procedures required for cardiovascular patient.

Observation check-list covered the following procedures:

-Nursing practice concerning:

Electrocardiogram (ECG).

Cardiopulmonary Resuscitation (CPR).

Oxygen therapy.

Drug and fluid administration, (Intravenous, subcutaneous injection).

Care for cannula.

Nurses general precaution for prevent infection .

The observation check-list was completed by the researcher. This tool was used as pre, post and follow up tests.

Scoring system: in the observation checklists, the items "not done" and "done" were scored " 0 " and "1", respectively. For each part, the scores of the items were summed-up and the total divided by the number of the items, giving a mean score for the part. These scores were converted into a percent score and means standard deviations were computed. The performance was considered adequate if the percent score was $65 \%$ or more and inadequate if less than $65 \%$.

This tool was used before implementation of the program to assess nurses' performance. It was then re-used immediately after the implementation of the program as well as three months later to evaluate the impact of the training program on nurses' performance. 


\section{Methods of data collection \\ Preparatory phase and administrative design:}

An official approval was obtained from the Dean of the Faculty of Nursing, Assiut University to the head of the department of cardiology at Assiut University hospital, to carry out the study, explained the purpose of the study, and asking for permission to conduct the study.

\section{Pilot Study:}

After developing the study tools. A Pilot study included 6 nurses was carried out to ensure clarity , applicability of the developed tools, and to estimate the time required to fill the questionnaire. Based on the results of the pilot study, the necessary modifications were done. Nurses who included in the pilot study were not excluded from the study sample using a new questionnaire sheet.

\section{Ethical considerations:}

Nurses were informed with the purpose and nature of the study and have ethical rights to participate or refuse participation in the study. Confidentiality of the information and oral consent from nurses to participate in the study had done.

\section{The intervention program:}

The researcher designed the proposed training program after literature review (nursing textbooks, journals, internet resources.) about cardiovascular diseases. Assessment of nurse's knowledge and performance in this regard, then the final form of the proposed program was checked by a panel of experts of medical and nursing to assess the program out line, objectives, strategy and evaluation plans. Their considerations preplanning and re-writing of the content was carried out according to the views set by the experts.

\section{Implementation of the program:}

To facilitate the implementation of the training program about cardiovascular diseases, researchers selected the training places, also teaching aids and media (pictures, videotapes and handouts) prepared. This was followed by arranging for the training program schedule based on the contents of program, number of staff involved, time availability, shifts as well as the resource available.

At initial interview the researcher explains the nature, purpose of the educational training program and asks the nurses to fill the questionnaire sheet to assess nurse's knowledge before application of program. Also the researcher scheduled with them, the teaching sessions for theory and practice, the nurses were divided into small groups, and each group contains (3-8) nurses. The researcher chooses their optimal time for giving the training program whenever they have minimal workload.

The in-services training program was conducted from July 2012 till April 2013.

\section{Evaluation phase:}

Immediately after program implementation as well as after 3 months the nurses' knowledge and performance has been evaluated by the researchers through filling the study tools.

The researchers observed the nurses' performance continuously during actual work in the different units of the department of cardiology from the beginning of morning shift until its end.

\section{Statistical Methods:}

The data obtained were reviewed, prepared for computer entry, coded analyzed and tabulated. Data analysis was done by using SPSS version 16 and clearing of data was done then data analysis was started by descriptive statistics such as frequencies, percentages and mean. After that cross tabulation and application of p-value by using Chi-square test used to test as a significant test. If the result of $p$-value was less than or equal 0.05 , it was considered statistical significance but if it was more than 0.05 considered statistical significance not significant. 


\section{Results:}

Table (1) : Distribution of nurses regarding their sociodemographic characteristics in Cardiovascular Department $(n=60)$.

\begin{tabular}{|c|c|c|}
\hline Variables & No. & $\%$ \\
\hline \multicolumn{3}{|l|}{ Age: } \\
\hline$<25$ years & 29 & 48.3 \\
\hline $25-<30$ years & 13 & 21.7 \\
\hline$\geq 30$ years & 18 & 30.0 \\
\hline Mean \pm SD (Range) & \multicolumn{2}{|c|}{$26.62 \pm 6.32(19-49)$} \\
\hline \multicolumn{3}{|l|}{ Marital status: } \\
\hline Married & 42 & 70.0 \\
\hline Unmarried & 18 & 30.0 \\
\hline \multicolumn{3}{|l|}{ Years of experience: } \\
\hline$<5$ years & 16 & 26.6 \\
\hline $5-<10$ years & 22 & 36.7 \\
\hline$\geq 10$ years & 22 & 36.7 \\
\hline Mean \pm SD (Range) & \multicolumn{2}{|c|}{$8.30 \pm 5.39(1-21)$} \\
\hline \multicolumn{3}{|l|}{ Level of education: } \\
\hline Diploma & 48 & 80.0 \\
\hline Technical institute & 8 & 13.4 \\
\hline Bachelor & 2 & 3.3 \\
\hline Postgraduate & 2 & 3.3 \\
\hline \multicolumn{3}{|l|}{ Attending training courses: } \\
\hline Yes & 21 & 35.0 \\
\hline No & 39 & 65.0 \\
\hline \multicolumn{3}{|l|}{ Number of training courses: } \\
\hline One & 11 & 52.4 \\
\hline More than one & 10 & 47.6 \\
\hline \multicolumn{3}{|l|}{ Place of work: } \\
\hline $\mathrm{CCU}$ & 31 & 51.7 \\
\hline Cardiac catheterization & 13 & 21.6 \\
\hline Cardiac Department & 16 & 26.7 \\
\hline
\end{tabular}

Table (2): Nurses knowledge about cardiovascular disease in pre, post, and follow-up test in Cardiovascular Department $(n=60)$.

\begin{tabular}{|l|c|c|c|c|c|c|c|c|}
\hline \multirow{2}{*}{ Knowledge Items } & \multicolumn{2}{c|}{ Pre-test } & \multicolumn{2}{c|}{ Post-test } & \multicolumn{2}{c|}{ Follow-up } & \multirow{2}{*}{$\mathbf{P}_{\mathbf{1}}$} & \multirow{2}{*}{$\mathbf{P}_{\mathbf{2}}$} \\
\cline { 2 - 9 } & $\mathbf{N o .}$ & $\mathbf{\%}$ & $\mathbf{N o .}$ & $\mathbf{\%}$ & $\mathbf{N o .}$ & $\mathbf{\%}$ & & \\
\hline Definition of the heart & 47 & 78.3 & 60 & 100.0 & 60 & 100.0 & $0.000^{*}$ & $0.000^{*}$ \\
\hline Anatomy of the heart & 50 & $\mathbf{8 3 . 3}$ & 60 & 100.0 & 60 & 100.0 & $0.001^{*}$ & $0.001^{*}$ \\
\hline Contents of the circulatory system & 19 & 31.7 & 48 & 80.0 & 43 & 71.7 & $0.000^{*}$ & $0.000^{*}$ \\
\hline Function of the heart & 55 & 91.7 & 60 & 100.0 & 59 & 98.3 & 0.068 & 0.209 \\
\hline Definition of cardiovascular disease & 28 & $\mathbf{4 6 . 7}$ & 60 & 100.0 & 60 & 100.0 & $0.000^{*}$ & $0.000^{*}$ \\
\hline Types of cardiovascular: disease & 15 & 25.0 & 53 & 88.3 & 38 & 63.3 & $0.000^{*}$ & $0.000^{*}$ \\
\hline Risk factors for cardiovascular disease & 16 & $\mathbf{2 6 . 7}$ & 59 & 98.3 & 53 & 88.3 & $0.000^{*}$ & $0.000^{*}$ \\
\hline Symptoms of cardiovascular disease & 7 & 11.7 & 58 & 96.7 & 49 & 81.7 & $0.000^{*}$ & $0.000^{*}$ \\
\hline Diagnoses of heart disease & 29 & 48.3 & 58 & 96.7 & 60 & 100.0 & $0.000^{*}$ & $0.000^{*}$ \\
\hline Complications of the CVD & 1 & 1.7 & 53 & 88.3 & 54 & 90.0 & $0.000^{*}$ & $0.000^{*}$ \\
\hline How to know that the patient breathes & 5 & 8.3 & 56 & 93.3 & 53 & 88.3 & $0.000^{*}$ & $0.000^{*}$ \\
\hline Aims for CPR & 0 & $\mathbf{0 . 0}$ & 58 & 96.7 & 56 & 93.3 & $0.000^{*}$ & $0.000^{*}$ \\
\hline Number of chest compressions to breaths & 22 & 36.7 & 56 & 93.3 & 56 & 93.3 & $0.000^{*}$ & $0.000^{*}$ \\
\hline
\end{tabular}




\begin{tabular}{|c|c|c|c|c|c|c|c|c|}
\hline \multirow{2}{*}{ Knowledge Items } & \multicolumn{2}{|c|}{ Pre-test } & \multicolumn{2}{|c|}{ Post-test } & \multicolumn{2}{|c|}{ Follow-up } & \multirow{2}{*}{$\mathbf{P}_{1}$} & \multirow{2}{*}{$\mathbf{P}_{2}$} \\
\hline & No. & $\%$ & No. & $\%$ & No. & $\%$ & & \\
\hline Complications of CPR & 0 & 0.0 & 52 & 86.7 & 55 & 91.7 & $0.000^{*}$ & $0.000 *$ \\
\hline Factors affect the ECG & 19 & 31.7 & 59 & 98.3 & 56 & 93.3 & $0.000^{*}$ & $0.000 *$ \\
\hline Ways to give oxygen to the patient & 8 & 13.3 & 53 & 88.3 & 54 & 90.0 & $0.000^{*}$ & $0.000^{*}$ \\
\hline Signs of digoxn poisoning & 1 & 1.7 & 60 & 100.0 & 59 & 98.3 & $0.000 *$ & $0.000^{*}$ \\
\hline
\end{tabular}

Chi-square test used. $\quad *$ Statistical significant difference at P-value $\leq 0.05$.

$\mathrm{P}_{1}$ : pre / post test. $\quad \mathrm{P}_{2}$ : post test / follow up test.

Table (3) : Distribution of nurses knowledge about health education regarding cardiovascular diseases in pre, post , and follow-up test in Cardiovascular Department $(n=60)$.

\begin{tabular}{|l|c|c|c|c|c|c|c|c|}
\hline \multirow{2}{*}{ Items } & \multicolumn{2}{|c|}{ Pre-test } & \multicolumn{2}{c|}{ Post-test } & \multicolumn{2}{c|}{ Follow-up } & \multirow{2}{*}{$\mathbf{P}_{\mathbf{1}}$} & \multirow{2}{*}{$\mathbf{P}_{\mathbf{2}}$} \\
\cline { 2 - 9 } & $\mathbf{N o .}$ & $\mathbf{\%}$ & $\mathbf{N o .}$ & $\mathbf{\%}$ & $\mathbf{N o .}$ & $\mathbf{\%}$ & & \\
\hline Using nitroglycerine. & 0 & $\mathbf{0 . 0}$ & 49 & 81.7 & 44 & 73.3 & $0.000^{*}$ & $0.000^{*}$ \\
\hline Using Digoxn & 0 & $\mathbf{0 . 0}$ & 58 & 96.7 & 60 & 100.0 & $0.000^{*}$ & $0.000^{*}$ \\
\hline Using anti-clotting drugs & 5 & 8.3 & 57 & 95.0 & 54 & 90.0 & $0.000^{*}$ & $0.000^{*}$ \\
\hline The benefits of quitting smoking & 5 & 8.3 & 60 & 100.0 & 56 & 93.3 & $0.000^{*}$ & $0.000^{*}$ \\
\hline The importance of a nutrition education & 7 & 11.7 & 60 & 100.0 & 59 & 98.3 & $0.000^{*}$ & $0.000^{*}$ \\
\hline Allowed Foods for CV patients & 11 & $\mathbf{1 8 . 3}$ & 59 & 98.3 & 60 & 100.0 & $0.000^{*}$ & $0.000^{*}$ \\
\hline Control of diabetes mellitus & 15 & $\mathbf{2 5 . 0}$ & 58 & 96.7 & 56 & 93.3 & $0.000^{*}$ & 0.000 \\
\hline Control of high blood pressure & 13 & $\mathbf{2 1 . 7}$ & 53 & 88.3 & 53 & 88.3 & $0.000^{*}$ & $0.000^{*}$ \\
\hline Physical activity & 2 & 3.3 & 43 & 71.7 & 47 & 78.3 & $0.000^{*}$ & $0.000^{*}$ \\
\hline Sex relationship & 0 & $\mathbf{0 . 0}$ & 57 & 95.0 & 57 & 95.0 & $0.000^{*}$ & $0.000^{*}$ \\
\hline Defecation & 1 & 1.7 & 57 & 95.0 & 52 & 86.7 & $0.000^{*}$ & $0.000^{*}$ \\
\hline
\end{tabular}

Chi-square test used. $\quad *$ Statistical significant difference at P-value $\leq 0.05$.

$\mathrm{P}_{1}$ : pre / post test. $\quad \mathrm{P}_{2}$ : post test / follow up test.

Table (4) : Score of nurses' performance regarding cardiovascular disease in pre, post, and follow-up test at in Cardiovascular Department $(n=60)$.

\begin{tabular}{|c|c|c|c|c|c|c|c|}
\hline \multirow{2}{*}{ performance items } & \multicolumn{2}{|c|}{ Pre-test } & \multicolumn{2}{|c|}{ Post-test } & \multicolumn{2}{|c|}{ Follow-up } & \multirow{2}{*}{ P-value } \\
\hline & No. & $\%$ & No. & $\%$ & No. & $\%$ & \\
\hline \multicolumn{7}{|l|}{ ECG: } & \multirow{4}{*}{$0.000 *$} \\
\hline Poor & 1 & 1.7 & 0 & 0.0 & 0 & 0.0 & \\
\hline Satisfactory & 55 & 91.7 & 0 & 0.0 & 0 & 0.0 & \\
\hline Good & 4 & 6.7 & 60 & 100.0 & 60 & 100.0 & \\
\hline \multicolumn{7}{|l|}{ Oxygen therapy: } & \multirow{4}{*}{$0.000 *$} \\
\hline Poor & 35 & 58.3 & 0 & 0.0 & 0 & 0.0 & \\
\hline Satisfactory & 23 & 38.3 & 1 & 1.7 & 2 & 3.3 & \\
\hline Good & 2 & 3.3 & 59 & 98.3 & 58 & 96.7 & \\
\hline \multicolumn{7}{|l|}{ CPR: } & \multirow{4}{*}{$0.000 *$} \\
\hline Poor & 8 & 13.3 & 0 & 0.0 & 0 & 0.0 & \\
\hline Satisfactory & 41 & 68.3 & 0 & 0.0 & 0 & 0.0 & \\
\hline Good & 11 & 18.3 & 60 & 100.0 & 60 & 100.0 & \\
\hline \multicolumn{7}{|l|}{ Cannula: } & \multirow{4}{*}{$0.000 *$} \\
\hline Poor & 4 & 6.7 & 0 & 0.0 & 0 & 0.0 & \\
\hline Satisfactory & 53 & 88.3 & 0 & 0.0 & 1 & 1.7 & \\
\hline Good & 3 & 5.0 & 60 & 100.0 & 59 & 98.3 & \\
\hline \multicolumn{7}{|l|}{ Drug and fluid administration: } & \multirow{4}{*}{$0.000 *$} \\
\hline Poor & 3 & 5.0 & 0 & 0.0 & 0 & 0.0 & \\
\hline Satisfactory & 49 & 81.7 & 0 & 0.0 & 0 & 0.0 & \\
\hline Good & 8 & 13.3 & 60 & 100.0 & 60 & 100.0 & \\
\hline
\end{tabular}




\begin{tabular}{|c|c|c|c|c|c|c|c|}
\hline \multirow{2}{*}{ performance items } & \multicolumn{2}{|c|}{ Pre-test } & \multicolumn{2}{|c|}{ Post-test } & \multicolumn{2}{|c|}{ Follow-up } & \multirow[b]{2}{*}{ P-value } \\
\hline & No. & $\%$ & No. & $\%$ & No. & $\%$ & \\
\hline \multicolumn{7}{|l|}{ Subcutaneous injection: } & \multirow{4}{*}{$0.000 *$} \\
\hline Poor & 14 & 23.3 & 0 & 0.0 & 0 & 0.0 & \\
\hline Satisfactory & 42 & 70.0 & 1 & 1.7 & 1 & 1.7 & \\
\hline Good & 4 & 6.7 & 59 & 98.3 & 59 & 98.3 & \\
\hline \multicolumn{7}{|l|}{ Hand washing: } & \multirow{4}{*}{$0.000 *$} \\
\hline Poor & 36 & 60.0 & 1 & 1.7 & 0 & 0.0 & \\
\hline Satisfactory & 23 & 38.3 & 6 & 10.0 & 10 & 16.7 & \\
\hline Good & 1 & 1.7 & 53 & 88.3 & 50 & 83.3 & \\
\hline \multicolumn{7}{|l|}{ Wearing gloves and masking: } & \multirow{4}{*}{$0.000 *$} \\
\hline Poor & 19 & 31.7 & 0 & 0.0 & 1 & 1.7 & \\
\hline Satisfactory & 28 & 46.7 & 0 & 0.0 & 0 & 0.0 & \\
\hline Good & 13 & 21.7 & 60 & 100.0 & 59 & 98.3 & \\
\hline \multicolumn{7}{|l|}{ Environmental condetion: } & \multirow{4}{*}{$0.000^{*}$} \\
\hline Poor & 43 & 71.7 & 0 & 0.0 & 1 & 1.7 & \\
\hline Satisfactory & 14 & 23.3 & 3 & 5.0 & 5 & 8.3 & \\
\hline Good & 3 & 5.0 & 57 & 95.0 & 54 & 90.0 & \\
\hline
\end{tabular}

Chi-square test used.

$P_{1}$ : pre / post test.
* Statistical significant difference at $\mathbf{P}$-value $\leq \mathbf{0 . 0 5}$.

$P_{2}$ : post test / follow up test.

Table (5) : Total score of nurses Knowledge regarding cardiovascular disease in pre, post, and follow-up test at in Cardiovascular Department $(n=60)$.

\begin{tabular}{|c|c|c|c|c|c|c|c|c|}
\hline & \multicolumn{2}{|c|}{ Pre-test } & \multicolumn{2}{|c|}{ Immediate Post-test } & \multicolumn{2}{|c|}{ Follow-up } & \multirow{2}{*}{ P-value ${ }^{1}$} & \multirow{2}{*}{ P-value $^{2}$} \\
\hline & No. & $\%$ & No. & $\%$ & No. & $\%$ & & \\
\hline Good & 3 & 5.0 & 56 & 93.3 & 51 & 85.0 & \multirow{3}{*}{$0.000 *$} & \multirow{3}{*}{$0.000 *$} \\
\hline Satisfactory & 32 & 53.3 & 4 & 6.7 & 7 & 11.7 & & \\
\hline Poor & 25 & 41.7 & 0 & 0.0 & 2 & 3.3 & & \\
\hline
\end{tabular}

Chi-square test used. $\quad *$ Statistical significant difference at $\mathbf{P}$-value $\leq \mathbf{0 . 0 5}$.

$P_{1}$ : pre / post test. $\quad P_{2}$ : post test / follow up test.

Table (6): Total score of nurses knowledge regarding health education for cardiovascular patient in pre, post, and follow-up test at in Cardiovascular Department $(n=60)$.

\begin{tabular}{|c|c|c|c|c|c|c|c|c|}
\hline & \multicolumn{2}{|c|}{ Pre-test } & \multicolumn{2}{|c|}{ Immediate Post-test } & \multicolumn{2}{|c|}{ Follow-up } & \multirow{2}{*}{ P-value ${ }^{1}$} & \multirow{2}{*}{ P-value ${ }^{2}$} \\
\hline & No. & $\%$ & No. & $\%$ & No. & $\%$ & & \\
\hline Good & 0 & 0.0 & 57 & 95.0 & 55 & 91.7 & \multirow{3}{*}{$0.000 *$} & \multirow{3}{*}{$0.000 *$} \\
\hline Satisfactory & 8 & 13.3 & 1 & 1.7 & 2 & 3.3 & & \\
\hline Poor & 52 & 86.7 & 2 & 3.3 & 3 & 5.0 & & \\
\hline
\end{tabular}

Chi-square test used. $\quad *$ Statistical significant difference at $\mathbf{P}$-value $\leq \mathbf{0 . 0 5}$.

$P_{1}$ : pre / post test. $\quad P_{2}$ : post test / follow up test. 
Figure (1): Relation between nurses knowledge about cardiovascular disease and years of experiences in Cardiovascular Department $(n=60)$.

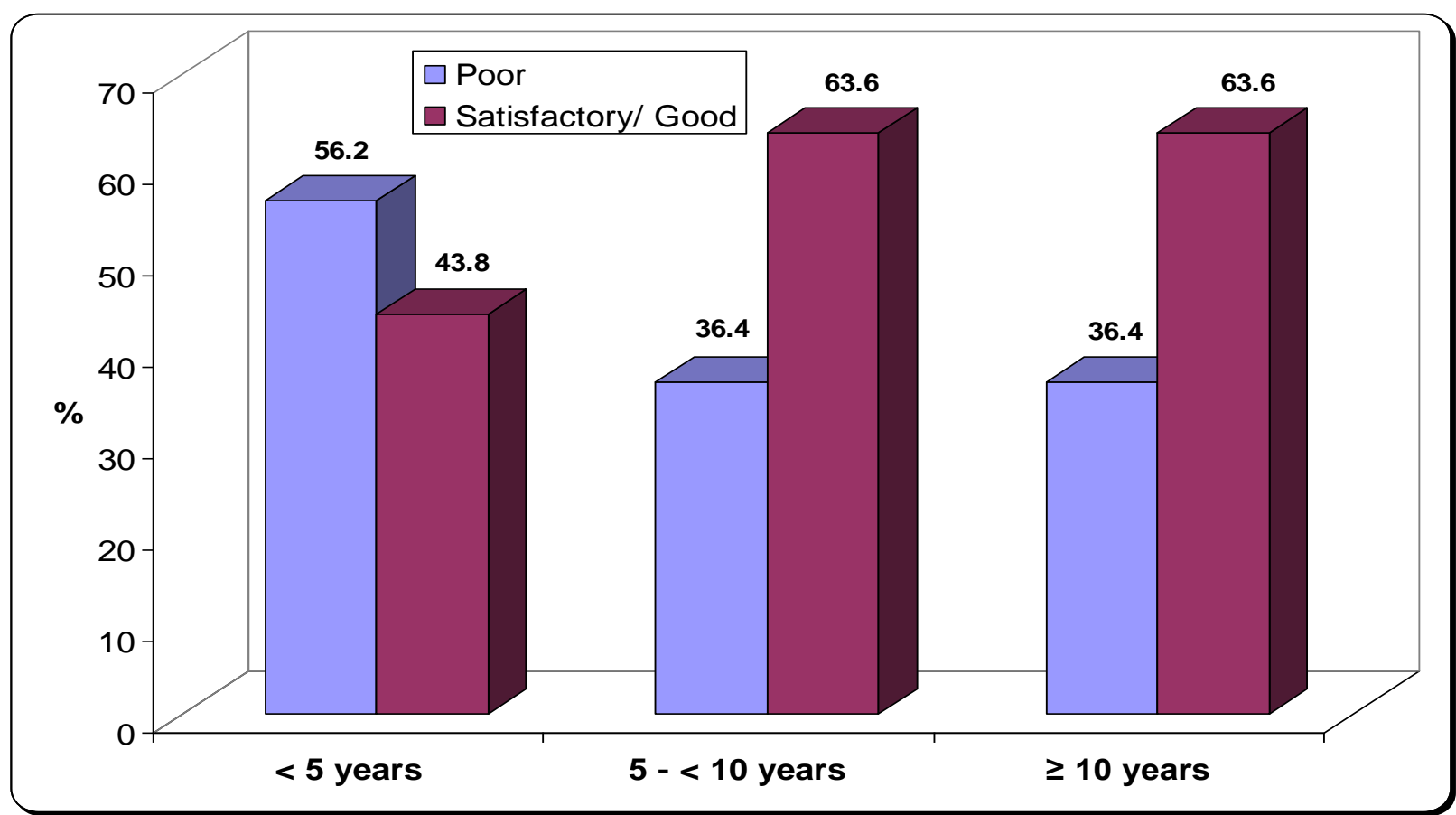

Figure (2): Relation between nurses knowledge about health education given to cardiovascular patients and their age in Cardiovascular Department $(n=60)$.

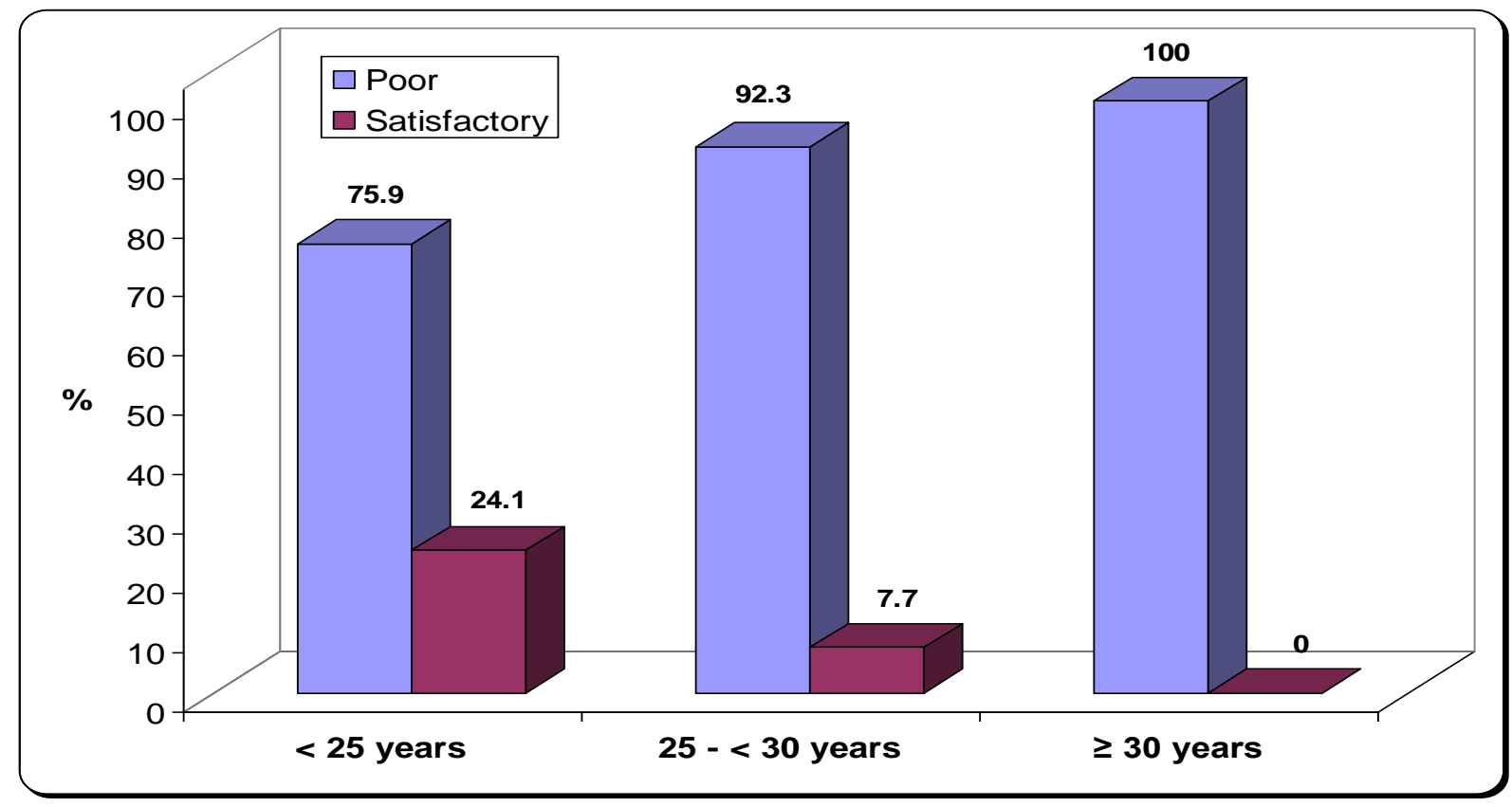


Table (1): Illustrates that, less than half of nurses $(48.3 \%)$ were younger than 25years the maen nurses age $(26.62 \pm 6.32)$. About one third of them $(35.0 \%)$ had got in-service training courses related to cardiovascular disease. More than half (51.7\%) of nurses work in the coronary care unit.

Table (2): Shows that more than one quarter of the nurses $(26.7 \%)$ know the risk factors of cardiovascular disease in pre test, improved to $(98.3 \%)$ in post test and $(88.3 \%)$ in follow up test. All the nurses did not know the complication of cardiopulmonary resuscitation in pre test, improved in post test to $(88.3 \%$ ) and follow up test to $(90.0 \%)$. Just one from the total nurses $(1.7 \%)$ was know the signs of digoxn poisoning in pre test but improved in the post test to (100.0\%) and (98.3\%) in follow up test. Highly statistical significant difference between pre, post and follow up test, with $\mathrm{P}$ value = $(0.000)$ in all knowledge items.

Table (3): Illustrates that all the nurses had poor knowledge about health education in all items given to the patient about using nitroglycerin in the pre test and improved in post test to $(81.7 \%)$. In pre test all nurses knowledge were poor about health education items given to the patient about sexual relationship but they improved to (95\%) in post test and follow up test. With highly statistical significant difference between pre, post and follow up test, with $\mathrm{P}$ value = (0.00) in all items .

Table (4): This table represents total score of nurses performance regarding cardiovascular disease in pre, post, and follow-up test. It was clear that there is highly statistical significant difference between pre test and post test ,the same finding exist between pre test and follow up test for each item of the study after educational training program.

Table (5): Total score of nurses Knowledge regarding cardiovascular disease in pre, post, and follow-up test at in Cardiovascular Department. It was found that $93.3 \%$ of study participants were good in post test and $85.0 \%$ in follow up test. It was found that there is highly statistical significant difference between pre test and post test, the same finding exist between pre test and follow up test after the educational training program.

Table (6): Total score of nurses knowledge regarding the education training program for cardiovascular patient in pre, post, and follow-up test at Cardiovascular Department . It was found that $95.0 \%$ of study participants were good in post test and $97.1 \%$ in follow up test

It was found that that there is highly statistical significant difference between pre test and post test ,the same finding exist between pre test and follow up test after educational training program.
Figure (1): Shows the relationship between the nurses knowledge about cardiovascular (CVD) disease and their years of experiences, it indicates that There is no statistical significant difference between years of experience of the nurses and their knowledge about (CVD) $\mathrm{P}$ value $=0.385$.

Figure (2): shows the relation between nurses knowledge about health education given to cardiovascular patients and their age; it indicate that all the nurses $(100.0 \%)$ who their age more than 30 years were had poor knowledge in health education about cardiovascular disease (CVD). While (24.1\%) who their age less than 25 years were had satisfactory knowledge in health education about cardiovascular disease (CVD). There is statistical significant difference between age of the nurses and their knowledge about health education given about $\mathrm{CV}$ patient $\mathrm{P}$ value $=0.048$.

\section{Discussion:}

Cardiovascular disease is a major cause of disability and premature death throughout the world, and contributes substantially to the escalating costs of health care. The underlying pathology is atherosclerosis, which develops over many years and is usually advanced by the time symptoms occur, generally in middle age. Acute coronary and cerebrovascular events frequently occur suddenly, and are often fatal before medical care can be given. Modification of its risk factors has been shown to reduce mortality and morbidity in people with diagnosed or undiagnosed cardiovascular disease, (WHO, 2013).

Educational training programs are considered as a mean for providing nurses with theoretical and technical information needed to acquire new skills and to continually improve their nursing practice. They also help them to accept their reasonability's for their professional development (Guibbert 2002).

The present study was under taken to identify and analyze the learning needs of nursing personnel, which helped us to know the nurse's awareness of their learning needs, and thus determining the content of an in-service education programs on cardiac nursing.

The current study revealed that there is lack of knowledge and practices as regards to cardiovascular diseases and before the application of educational training program. Most nurses in department of cardiology had got unsatisfactory knowledge level about cardiovascular disease while all of them had good knowledge score in post test and follow up tests. 
Regarding nurses knowledge about cardiovascular disease the researchers found that the studied nurses had poor knowledge about types, risk factors, symptoms and complication of cardiovascular disease in pre test, they improved in post and follow up test. This finding agree with Albert, (2002) who stated that in order for effective patient education to take place the nurse needs an optimum knowledge. This finding were emphasized by Youssef, (2007) who reported that after implementation of the teaching protocol, nurses' knowledge score levels were significantly improved. In Assiut, Mohamed (2001) and Masoud (2006) stressed that "in-service" educational and training programs have significant favorable impact in improving nurses' knowledge, they also recommended that educational programs should be continuously organized according to the needs of nurses, with subsequent continuing evaluation to the progress and outcome of these programs.

Also, the results represented that all nurses had poor knowledge about health education given to the patient about using digoxn in pre test but improved in post and follow up test. In this line Todd et al., (2005) stated that digoxin was associated with a higher risk of death and heart failure (HF) hospitalization; however these risks were dependent on serum digoxin concentration (SDC). Patients hospitalized for the treatment of heart failure who received targeted patient education delivered by a nurse educator were less likely to be rehospitalized during a 180-day follow-up period. And agree with Mahany, (2012) who found that nurses had poor knowledge regarding medications and their study demonstrated the need to provide more education on medications to nursing staff.

In pre test all nurses had poor knowledge about health education given to cardiovascular patient about sexual relationship but the results improved in post test and follow up test. Nurses didn't feel competent to provide sexual counseling and as a result are reluctant to do so. Sexual counseling is frequently overlooked or ignored in rehabilitation programs for cardiac patients, not because there is a lack of literature or guidelines on this topic, but because of the nurses' discomfort at entering this sensitive area even though they may agree in principle that they have some responsibility for providing sexual counseling. In this line Vassiliadou et al., (2008) suggested that the resumption of sexual activity is an important aspect of quality of life for many cardiac patients. Managing the fears and worries of patients and their partners is an important part of educating the patient; health professionals are too often unwilling to discuss such a personal issue with the patient.
This study represents that the minority $(6.7 \%)$ of the studied nurses were good in ECG performance while $(91.7 \%)$ of them were satisfactory in pre test and improved in the post and follow up test after inservice training program. This result agree with Osman , (2001) who reported that before program implementation the nurses had a little knowledge scores suitable to ECG performance.

Regarding hand washing it was found that $(60.0 \%)$ from the studied nurses had poor score in pre test but $(88.3 \%)$ of them had good score in post and follow up test. In this respect Osman (2001) documented that the lacking of hand washing could be attributed to lack of nurses knowledge about the importance of hand washing to prevent infection. In this line Berguer and Heller, ( 2004) stated that, since most infections occur with direct patient contact, proper hand hygiene (hand washing or using alcohol-based rubs) remains the single most effective way to prevent infection to and from patients.

These findings agree with Mohammed, (2010) who reported that only $5.2 \%$ of the studied sample know that hand must be washed after contact with blood and body fluids. And disagree with El-shenawi, (2002) who found that the mean percentage of nurses knowledge regarding hand decontamination was very good. Nurses in all roles and settings can demonstrated leadership in infection prevention and control by using their knowledge, skill and judgment to initiate appropriate and immediate infection control procedures. Health care workers were at a high risk of needle stick injury blood born pathogens Beltrami et al., (2000).

Nurses' exhaustion, prolonged working hours and lack of incentives. This is supported by Teleb, (2001) and Emam et al., (2004) who stated that among factors contributed to lack of nurses knowledge is loss of enthusiasm due to lack of rewarding system and prolonged working hours.

Concerning the unsatisfactory nurses' knowledge in pretest study results, this finding is agree with Teleb, (2001) who found unsatisfactory knowledge level of nurses regarding teaching program about myocardial infarction (MI) before program implementation. And with Laxmi (2002) who stated that nurses need to be given special training in caring for the cardiac patients in ordered to improve their knowledge. Also it was consistent with the findings of Washburn, et al., (2005) who mentioned that nurses were not knowledgeable before participating in an education and communication intervention. This finding agreed with Willette,et al., (2007) who stated that nurses had unsatisfactory knowledge and they not adequately prepared to educate patients with heart failure HF about self management. 
In agreement with Emam et al., (2004) who reported that educational program has a good effect on improving the nurses' knowledge and performance. It was consistent with Albert, (2006) who stated that nurses' knowledge would increase after attending educational programs. Finally, the program has achieved its objectives by improving the knowledge of nurses. Moreover, improvement in nursing performance was noticed throughout the program phases.

\section{Conclusions:}

Based on the results of the present study, it was concluded that cardiac nurses in Cardiovascular Department at Assiut University Hospital were lacking the necessary basic knowledge and skills related to caring of patient with cardiovascular disease. There is highly statistically significant difference between the nurses knowledge about cardiovascular disease and health education given to the patient in pre, immediate post test and follow-up $(\mathrm{P}=0.000)$. Also there is statistically significant difference between the nurses practices in pre, immediate post test and follow-up $(\mathrm{P}=0.000)$. Implementation of the program was associated with significant improvements of nurses' knowledge and practice. Therefore, the program was successful in correcting the deficiency in nurses' knowledge and performance regardless to their personal and job characteristics.

\section{Recommendations:}

Based on results of the present study the following can be recommended: Continuous training programs contain knowledge, health education and practices about cardiovascular disease, which will be reflected on better outcome and service for inpatients. Periodic monitoring of nurses knowledge and practice about universal precaution to evaluate level of performance. Newly employed nurses in Cardiovascular Department are required to successfully complete a test of basic knowledge and skills before assuming independent responsibility for patient care.

\section{References:}

1. Albert N., (2006): Evidence-based nursing care for patients with heart failure. Adv Crit Care J, 17 (2): 170-183.

2. Beltrami E., Williams I.T., Shpiro C.N., and Chamberland M., (2000): Risk and management of blood-borne infection in health care workers, ClinMicrobiol Rev, 13(9): 385 407.
3. Berguer R., and Heller P. (2004): Preventing sharps injuries in the operating room. J. Am. Coll. Surg, 199: 462-467.

4. Chin P., (2008): Integrated theory and knowledge development in nursing (7th ed.). St. Louis, MO: Mosby. Pp. 371-73.

5. El-shenawi S., (2002): Establishing standers for prevention and control of nosncomial infection in the intensive care unit at Alexandria main university hospital, doctorate thesis, Faculty of Nursing, Alexandria University.

6. Emam E., Hassan S., El - Mghazy D, and Mohamed N., (2004): effect of educational program of paramedical's knowledge and attitude toward infection control in El Minia city hospitals. Doctorate Thesis, Faculty of Nursing, Assuit University.

7. Guibbert A., (2002): Using your clinical expertise in nursing education. Clinical Nurse Specialist, 16 (5): 242-246.

8. laxmi K., (2002): "Knowledge of nursing personnel on first 24 hours care of patients with myocardial infarction in Hyderabad". published thesis NTR University of health sciences Vijay Wada. pp. 98.

9. Mahany A., (2012): Teaching program about myocardial infarctions for nurses of coronary care units at Minia University Hospital and Elamery Hospital, thesis of master degree in critical nursing, Assuit University.

10. Masoud E., (2006): The impact of Educational and Training Program on the knowledge and performance of nursing practice in the hematology and emergency unites at pediatric department of Assiut University Hospital, doctorate thesis, Assuit University.

11. Mendis, Shanthi. Puska, Pekka and Norrving, B., (2011): Global Atlason cardiovascular disease, Prevention and control of CVDs, Policies, strategies and interventions, Published by the World Health Organization in collaboration with the World Heart Federation and the World Stroke Organization . Section C, pp.69-76.

12. Michael B., (2013): Risk factors of cardiovascular disease. Nature j, 451, (7181): 903-957.

13. Mohamed A., (2001): The state of Nursing Care of Thalassemic Patients and the Design, Implementation and Evaluation of a Program to Upgrade Nursing Care for Thalassemic Patients. MSc Thesis, Pediatric Nursing. Assiut University Hospital.

14. Mohamed A., (2010): Assessment of nursing interventions for nurses working with Elderly burned patients as a basis for designing of an 
educational program for them in Assuit city Doctorate Thesis in Gerontological Nursing, Assuit University.

15. Mozaffarian D., Roger V., Benjamin E., Berry J., Borden W., (2013): Heart disease and stroke statistica report from the American Heart Association. Circulation, 127 (1): 6-245.

16. Osman S., (2001): Effect of an educational program about myocardial infarction on knowledge and performance of nurses, doctorate thesis, Assuit University.

17. Susan D., (2009): Fundamental Concepts and Skills for Nursing. Missouri: Saunders Elsevier. pp. 964. ISBN9781416052289

18. Teleb S., (2001): Effect of an educational program about myocardial infarction on knowledge and performance of nurses, doctorate thesis, Assuit University. pp. 119.

19. Todd M., Koelling, Monica L., Johnson R., Robert J., Cody, Keith D. and Aaronson, M., (2005): Discharge Education Improves Clinical Outcomes in Patients With Chronic Heart Failure Circulation, 111: 179-185.

20. Ulmer H., ( 2002): Perspectives of a Physician and Critical Care Nurse Centers for Disease Control and Prevention. Available athttp://en.wikipedia.org/wiki/Cardiac_arrest

21. Vassiliadou A., Stamatopoulou E., Triantafyllou G., Gerodimou E., Toulia G.and Pistolas D., (2008): The role of nurses in the sexual counseling of patients after myocardial infarction, Health Science Journal, 2 (2):125130.

22. Washburn S., Hornberger C., Klutman A., and Skinner L., (2005): Nurses' knowledge of heart failure education topics as reported in a small Midwestern community hospital. Journal of Cardiovascular Nursing, 20 (3): 215-220.

23. Willette E., Suxxells D., Davis L., and Bush C., (2007): nurses knowledge of hart failure self management. ProgCardiovascNurs. 2007 Fall; 22 (4): 190-5.

24. World Health Organization (WHO). (2003). Prevention of recurrent heart attacks and strokes in low and middle income populations. Evidence-based recommendations for policy makers and health professionals. Geneva, available at http://www.who.int/bookorders.

25. World Health Organization, (2011): Global atlas on cardiovascular disease prevention and control. Geneva, World Health Organization, 2011. Issue No. 1031 Egypt.

26. Youssef S., (2007): Microvascular free tissue transfer surgeries" Impact of a designed teaching protocol on nurse's knowledge, practices and patient's outcome. doctorate thesis, in Adult Nursing Assuit University. 